\title{
Audit Tata Kelola Teknologi Informasi Domain Monitor, Evaluate, and Asses dan Deliver, Service, Support Berdasarkan Framework COBIT 2019
}

\author{
Ike Pertiwi Windasari ${ }^{\mathrm{a}^{*}}$, Adian Fatchur Rochim ${ }^{\mathrm{b}}$, Septi Nurna Alfiani ${ }^{\mathrm{c}}$, Azizah Kamalia ${ }^{\mathrm{d}}$,

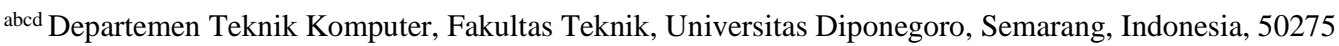

Naskah Diterima : 22 November 2020; Diterima Publikasi : 24 November 2021

DOI: 10.21456/vol11iss2pp131-138

\begin{abstract}
University is a form of tertiary institution that has a tridharma task to assist the government in handling and implementing development in all fields, especially education. Information technology and information systems tools are important to support the achievement of the university's vision and mission. University information technology governance is an activity used to measure existing information technology to support the achievement of university activity goals. The obstacle faced by the university is that every year it spends a large budget with activities related to information technology (IT) ranging from design, implementation, IT training for the entire academic community, but the results obtained cannot be measured. This research was conducted to measure the maturity of IT implementation at universities. In this study, using COBIT 2019 as a framework on the two domains of MEA and DSS in the research object university (PTOP). Two of these domains are expected to be able to measure the target Capability Level, Capability Level current and gaps (gap) The data source used is the results of interviews with IT governance authorities. The research object case study at one of the universities in Semarang, hereinafter referred to as the research object college (PTOP). Based on the research results, it was found that the PTOP capability level in the MEA and DSS domains was at level 1 or performed, which means that the process carried out had more or less reached the goal, but through the implementation of a series of activities that were less organized.
\end{abstract}

Keywords : COBIT 2019; Capability Level; Gap Analysis

\begin{abstract}
Abstrak
Universitas adalah salah satu bentuk perguruan tinggi yang memiliki tugas tridarma untuk membantu pemerintah dalam menangani dan melaksanakan pembangunan di segala bidang khususnya bidang pendidikan. Teknologi informasi dan sistem informasi merupakan tools yang penting untuk mendukung tercapainya visi dan misi universitas. Tata kelola teknologi informasi universitas merupakan kegiatan yang digunakan untuk mengukur teknologi informasi yang telah dimiliki untuk menunjang tercapainya tujuan kegiatan universitas. Kendala yang dihadapi oleh universitas adalah tiap tahun mengeluarkan anggaran yang besar dengan kegiatan-kegiatan terkait teknologi informasi (TI) mulai dari desain, implementasi, pelatihan TI bagi seluruh civitas akademika, namun hasil yang didapatkan belum dapat terukur. Penelitian ini dilakukan untuk mengukur kematangan implementasi TI pada universitas. Pada penelitian ini menggunakan COBIT 2019 sebagai kerangka kerja pada dua domain MEA dan DSS pada perguruan tinggi objek penelitiam (PTOP). Dua domain tersebut diharapkan dapat mengukur target Capability Level, Capability Level saat ini dan kesenjangan (GAP). Sumber data yang digunakan yaitu hasil wawancara terhadap pemegang otoritas tata kelola TI. Studi kasus obyek riset pada salah satu perguruan tinggi di Semarang, selanjutnya disebut perguruan tinggi obyek penelitian (PTOP). Berdasarkan hasil penelitian, didapatkan hasil level kapabilitas PTOP pada domain MEA dan DSS berada pada level 1 atau performed yang artinya proses yang dilakukan kurang lebih telah mencapai tujuan, namun melalui penerapan serangkaian kegiatan yang tidak lengkap dan tidak terlalu/kurang terorganisir.
\end{abstract}

Kata kunci: COBIT 2019; Level Kapabilitas; Analisis Gap

\section{Pendahuluan}

Menurut Juliandarini dan Sri (2013) pada saat ini teknologi informasi (TI) menjadi bagian yang sangat penting bagi perusahaan atau institusi dengan skala wirausaha. Perusahaan atau institusi menggunakan teknologi sebagai hal yang dapat mendukung rencana $\underline{\text { strategis untuk mencapai visi, misi dan tujuannya }}$ *) Penulis korespondensi: Ike@lecturer.undip.ac.id menurut Juliandarini dan Sri (2013). Perusahaan atau institusi setuju bahwa penyediaan teknologi informasi dapat memenuhi kebutuhan perusahaan dalam mencapai apa yang diperlukan dan meningkatkan kegiatan operasional. Fungsi teknologi informasi tidak hanya untuk meningkatkan operasional tetapi juga memberikan nilai tambah dan keunggulan yang kompetitif menurut Juliandarini dan Sri (2013). 
Dengan mengetahui pentingnya teknologi informasi, Perguruan Tinggi (PT) perlu mengimplementasikan TI ke dalam proses operasionalnya. TI dapat mendukung PT dalam bidang administrasi, kegiatan belajar mengajar (KBM), media komunikasi, dan membantu memperoleh hasil. Sehingga PT dapat meningkatkan kualitas layanan apabila menerapkan teknologi informasi yang baik.

Perguruan tinggi obyek penelitian (PTOP), merupakan salah satu universitas yang berlokasi di Semarang, merupakan salah satu universitas yang menggunakan TI dalam proses bisnisnya. Universitas tersebut cukup besar, memiliki 11 Fakultas dan satu lembaga program pascasarjana, dengan rincian 21 Program Studi Diploma III (D3), 49 Program Studi Sarjana (S1), 35 Program Studi Magister (S2), 18 Program Pendidikan Kedokteran Spesialis, 3 Program Profesional dan 13 program studi Doktor (S3). PTOP telah membuat rencana strategis yang memiliki titik sasaran untuk merealisasikan tujuan PTOP.

Kendala yang dihadapi oleh PTOP adalah tiap tahun mengeluarkan anggaran besar untuk inveestasi TI bagi seluruh sivitas akademika, namun hasil yang didapatkan belum/tidak terukur. Untuk mengetahui apakah PTOP telah memenuhi standar serta pelaksanaan yang sesuai, maka harus dilakukan penilaian atau audit terhadap teknologi informasi.

Penilaian tingkat kemampuan proses dan pembuatan rekomendasi pada PTOP dapat menggunakan kerangka kerja/framework COBIT 2019 sebagai dasar untuk meningkatan dan mengembangan tata kelola teknologi informasi. ISACA (2019) mengemukakan bahwa COBIT merupakan standar komprehensif yang membantu perusahaan mencapai tujuan mereka dan menghasilkan nilai melalui tata kelola dan manajemen teknologi informasi yang efektif. Penelitian ini menggunakan domain DSS (Deliver, Service, and Support) dan MEA (Monitor, Evaluasi dan Assess) pada COBIT 2019 dengan perhitungan nilai capability level untuk menghitung keselarasan tujuan TI.

Tujuan penelitian adalah untuk mengukur ketercapaian dari implementasi TI terkait dengan tujuan dari PTOP berdasarkan framework COBIT 2019. Diharapkan hasil laporan penilaian yang diperoleh dapat menjadi landasan pembuatan kerangka kerja tata kelola TI yang sesuai dengan kebutuhan PTOP.

Susunan makalah pada penelitian ini selanjutnya akan menjelaskan tentang penelitian-penelitian yang telah dilakukan, pengertian, definisi COBIT 2019. Kemudian dilanjutkan dengan bagian ketiga yaitu metodologi penelitian, sumber data, dan bagian keempat memaparkan hasil penelitian serta ditutup dengan bagian kelima yaitu kesimpulan.

\section{Kerangka Teori}

\subsection{Audit TI}

Audit pada dasarnya adalah proses sistematis dan obyektif dalam memperoleh dan mengevaluasi buktibukti tindakan ekonomi, guna memberikan asersi/pernyataan dan menilai seberapa jauh tindakan ekonomi sudah sesuai dengan kriteria yang berlaku dan mengkomunikasikan hasilnya kepada pihak terkait.

Audit teknologi informasi secara umum menurut Barkah et al., (2015) merupakan proses pengumpulan dan evaluasi dari semua kegiatan sistem informasi dalam organisasi. Istilah lain dari audit teknologi informasi adalah audit komputer yang banyak dipakai untuk menentukan apakah asset sistem informasi organisasi itu telah bekerja secara efektif dan integrative dalam mencapai target organisasinya.

Seperti pada Juliandarini et al., (2013), bahwa tujuan tata kelola TI adalah mengarahkan upaya TI, sehingga memastikan performa TI sesuai dengan pemenuhan keselarasan dan realisasi keuntungan perusahaan, pengeksploitasian peluang dan pemaksimalkan manfaat, kebertanggungjawaban dan manajemen tepat risiko.

Menurut Grembergen dan De Haes (2009) tata kelola perusahaan teknologi informasi (EGIT) adalah pendefinisian dan penanaman proses dan struktur di seluruh organisasi yang memungkinkan pelaku bisnis dan TI untuk melaksanakan tanggung jawab mereka dengan memaksimalkan dukungan keselarasan bisnis IT.

\subsection{COBIT 2019}

Menurut ISACA (2012) COBIT adalah suatu panduan kerja dalam pengelolaan teknologi informasi. COBIT 2019 merupakan sebuah kerangka yang membantu perusahaan dalam menciptakan nilai optimal teknologi informasi dengan menjaga keseimbangan penggunaan sumber daya.

Sebelum COBIT 2019, terdapat versi COBIT 5 yang dirilis pada tahun 2012. Adanya perkembangan teknologi dan bisnis baru dalam memanfaatkan teknologi informasi, membuat COBIT melakukan penyelarasan. Perbedaan utama antara COBIT 2019 dengan COBIT 5 yaitu prinsipnya. COBIT 5 berbasis pada lima prinsip. Prinsip tersebut adalah memenuhi kebutuhan para pemangku kepentingan (stakeholder), mencakup organisasi secara menyeluruh (end-to-end), menerapkan satu framework tunggal yang terpadu, memungkinkan pendekatan yang holistik, memisahkan tata kelola dengan manajemen.

Sedangkan di COBIT 2019, prinsip tersebut diperbarui menjadi dua sistem klasifikasi besar dimana prinsip COBIT 5 dikategorikan ke dalam sistem tata kelola atau governance system ditambah dua prinsip baru. Klasifikasi lainnya adalah kerangka kerja tata kelola atau governance framework. 
Perbedaan lainnya terletak pada beberapa obyektif baru pada COBIT 2019 yang sebelumnya pada COBIT 5 belum ada, yaitu APO14 (Managed data), BAI01 (Managed Programs) - pada COBIT 5 digabung dengan Managed Projects, BAI11 (Managed Projects) - pada COBIT 5 digabung dengan Managed Programs, dan yang terakhir MEA04 (Managed Assurance).

COBIT 2019 memiliki dua objectives yaitu Governance dan Management. Governance Objectives (tujuan tata kelola) memuat domain Evaluate, Direct, dan Monitor (EDM). Sedangkan Management Objectives memuat empat domain yaitu APO (Align, Plan, and Organize), BAI (Build, Acquare, and Implement), DSS (Deliver, Service and Support), dan MEA (Monitor, Evaluate, and Assess).

Penelitian ini hanya berfokus pada domain DSS dan MEA untuk mengaudit PTOP, karena domain MEA sangat penting penting untuk memantau kesesuaian kinerja dan teknologi informasi, sedangkan domain DSS untuk mengukur pelayanan teknologi informasi pada PTOP.

Domain Monitor, Evaluasi dan Assess (MEA) membahas pemantauan kinerja dan kesesuaian teknologi Informasi dengan target kinerja internal, tujuan kontrol internal, dan persyaratan eksternal.

- MEA01 - Kinerja terkelola dan pemantauan kesesuaian

- MEA02 - Sistem pengendalian internal yang terkelola

- MEA03 - Kepatuhan yang dikelola dengan persyaratan eksternal

- MEA04 - Jaminan terkelola

Domain Deliver, Service and Support (DSS) membahas pengiriman operasional dan dukungan layanan teknologi informasi, termasuk keamanan.

- DSS01 - Operasi yang dikelola

- DSS02 - Permintaan dan insiden layanan terkelola

- DSS03 - Masalah yang dikelola

- DSS04 - Kontinuitas terkelola

- DSS05 - Layanan keamanan terkelola

- DSS06 - Kontrol proses bisnis yang dikelola

Faktor Desain merupakan faktor yang mempengaruhi desain sistem tata kelola perusahaan serta memposisikannya agar berhasil dalam penggunaan teknologi Informasi. Faktor desain memiliki beberapa macam, yaitu Enterprise Strategy (strategi perusahaan) Enterprise Goals (tujuan perusahaan), Risk Profile (profil risiko), IT-Related Issues (isu terkait TI), Threat Landscape (lanskap ancaman), Compliance Requirements (persyaratan kepatuhan), Role of IT (peran TI), Sourcing model for IT (model sumber TI), IT Implementation Methods (metode implementasi TI), dan Technology Adoption Strategy (strategi adopsi TI) seperti yang ditampilkan pada Gambar 1.

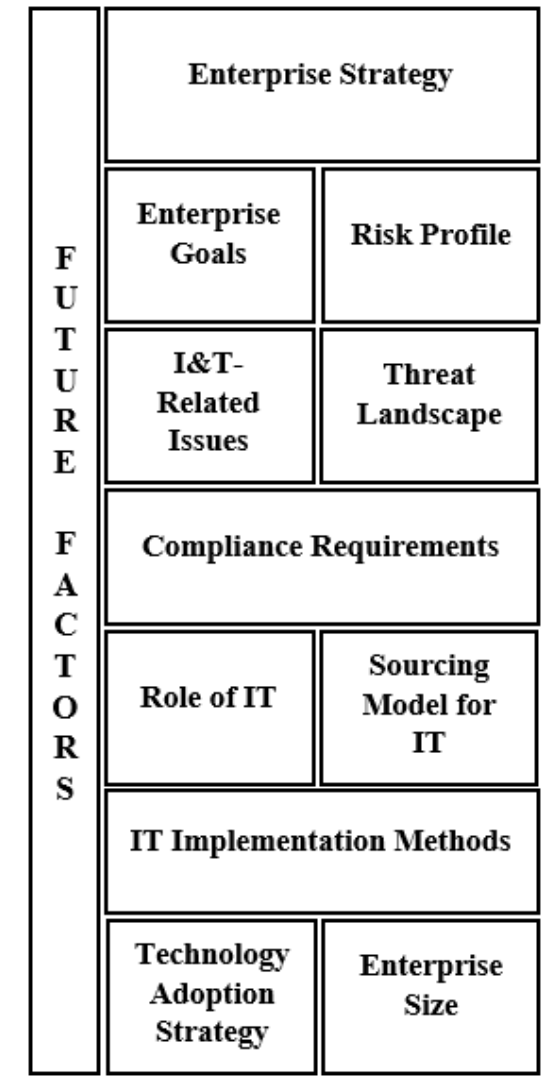

Gambar 1. Parameter - parameter faktor penentu keberhasilan organisasi (ISACA, 2018)

\subsection{Capability Level}

COBIT®2019 mendukung skema kapabilitas proses berbasis kapabilitas Maturity Model Integration $\left(\mathrm{CMMI}{ }^{\circledR}\right)$. Proses dalam setiap tujuan tata kelola dan manajemen dapat beroperasi pada berbagai tingkat kemampuan, mulai dari 0 hingga 5. Tingkat kemampuan adalah ukuran untuk seberapa baik proses diimplementasikan dan dilaksanakan.

- Level 0 (Incomplete): Kurangnya kemampuan dasar, pendekatan yang tidak lengkap untuk menangani tata kelola dan tujuan manajemen, mungkin atau tidak mungkin memenuhi maksud praktik proses apa pun

- Level 1 (Performed): Proses ini kurang lebih mencapai tujuannya melalui penerapan serangkaian kegiatan yang tidak lengkap yang dapat dikategorikan sebagai awal atau intuitif tidak terlalu terorganisir.

- Level 2 (Managed): Proses mencapai tujuannya melalui penerapan serangkaian kegiatan dasar yang lengkap yang dapat dikategorikan sebagai dilakukan.

- Level 3 (Estabilished): Proses mencapai tujuannya, didefinisikan dengan baik, kinerjanya diukur untuk meningkatkan kinerja dan perbaikan terus-menerus dilakukan. 
- Level 4 (Predictable): Proses mencapai tujuannya, didefinisikan dengan baik, dan kinerjanya diukur (secara kuantitatif).

- Level 5 (Optimizing): Proses mencapai tujuannya dengan cara yang jauh lebih terorganisir menggunakan aset organisasi. Proses biasanya didefinisikan dengan baik.

Capability level memiliki tingkatan yang dapat dilihat pada Tabel 1:

\begin{tabular}{clc} 
Tabel 1. Kode Capability Level & \\
\hline Kode & \multicolumn{1}{c}{ Management Objectives } & $\begin{array}{c}\text { Target capabbility } \\
\text { level }\end{array}$ \\
\hline $\mathrm{N}$ & $\begin{array}{l}\text { Not Achieved (Tidak } \\
\text { Tercapai) }\end{array}$ & $0 \%-15 \%$ \\
$\mathrm{P}$ & $\begin{array}{l}\text { Partially Achieved (Sebagian } \\
\text { Tercapai) }\end{array}$ & $15 \%-50 \%$ \\
$\mathrm{~L}$ & $\begin{array}{l}\text { Largely Achieved (Sebagian } \\
\text { Besar Tercapai) }\end{array}$ & $50 \%-85 \%$ \\
$\mathrm{~F}$ & $\begin{array}{l}\text { Fully Achieved (Sepenuhnya } \\
\text { Tercapai) }\end{array}$ & $85 \%-100 \%$ \\
\hline
\end{tabular}

\subsection{RACI Chart}

Menurut Hardiansyah et al. (2019) RACI adalah singkatan dari Responsible yaitu orang yang melakukan tugas/pekerjaan, Accountable yaitu orang yang bertanggung jawab pada tugas, Consulted yaitu orang yang berperan memberi masukan, dan Informed yaitu orang yang perlu mengetahui hasil atau keputusan yang diambil.

Seperti pada Setiaji dan Dewi (2016) RACI Chart terdiri empat parameter. Keempat parameter itu adalah responsible, orang yang melakukan tugas atau pekerjaan; accountable, orang yang bertanggung jawab pada suatu tugas atau pekerjaan dan memiliki wewenang untuk memutuskan suatu permasalahan atau perkara; consulted, yaitu orang yang memberikan masukan, pendapat atau kontribusi ketika diperlukan pada tugas atau pekerjaan tersebut; informed, yaitu orang yang perlu mengetahui tindakan dan hasil ataupun keputusan yang telah diambil.

Sugiyono (2008) mengungkapkan bahwa sampel adalah suatu bagian dari keseluruhan serta karakeristik yang dimiliki oleh sebuah populasi. Menurut Sudjana (2009) populasi adalah totalitas semua nilai yang mungkin, hasil yang menghitung ataupun pengukuran, kuantitatif maupun kualitatif mengenai karakteristik tertentu dari semua anggota kuumpulan yang lengkap dan jelas yang ingin mempelajari sifat-sifatnya. Teknik pengambilan sampel penelitian harus sesuai. Jenis teknik pengambilan yang dilakukan yaitu purposive sampling, dimana sampel penelitian dipilih menggunakan kriteria tertentu, seperti yang tercantum pada Sukirni (2012).

Pada penelitian ini, sumber data yang digunakan adalah data dari responden yang terkait langsung dalam implementasi tata kelola TI. Responden diambil dari populasi pengelola TI.

\section{Metode}

Metode yang digunakan pada penelitian ini adalah metodologi kualitatif dan kuantitatif. Menurut Anggito dan Setiawan (2018) penelitian kualitatif adalah pengumpulan data pada suatu latar alamiah dengan maksud menafsirkan fenomena yang terjadi dimana peneliti adalah sebagai instrumen kunci. Jenis metodologi kualitatif yang dignakan dalam penelitian ini yaitu kualitatif interaktif. Maksudnya adalah mengumpulkan data langsung dari orang yang bersangkutan dengan penelitian yang dilakukan (sampel penelitian). Sugiyono (2019) mengungkapkan bahwa metode kuantitatif adalah penelitian ilmiah secara sistematis, terencana, dan terstruktur terhadap bagian - bagian dan fenomena serta hubungan - hubungannya dengan jelas sejak awal hingga hasil akhir penelitian berdasarkan pengumpulan data informasi yang berupa simbol angka atau bilangan.

Metode pertama adalah kualitatif dengan metode wawancara kepada responden. Dilanjutkan metode kuantitatif untuk membuat skala nilai dari data kualitatif yang didapatkan.

\subsection{Tahapan Penelitian}

Agar peneliti disiplin untuk melakukan penelitian secara teratur dan bertahap, maka dibuat diagram alir penelitian seperti ditunjukkan pada Gambar 2.

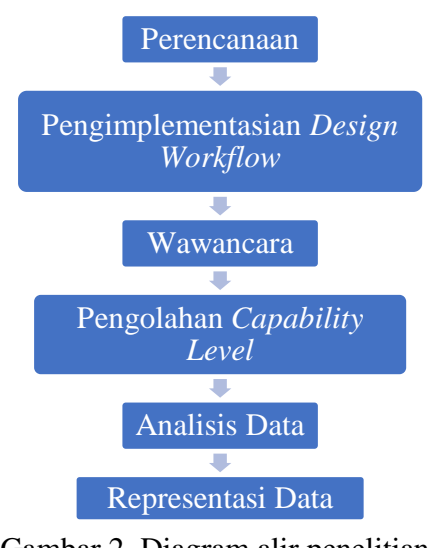

\subsection{Metode Pengumpulan Data}

Metode pengumpulan data yang digunakan dalam penulisan tugas akhir ini adalah sebagai berikut :

- Studi Literatur - Penelitian ini dilakukan dengan mencari dan mengumpulkan data, informasi, dan bahan - bahan yang diperoleh dari buku, literatur, dan artikel terkait metode COBIT 2019, IT Governance, metode penelitian, pengolahan data, dan sebagainya.

- Studi Lapangan - Studi lapangan yang dilakukan untuk memperoleh data sekunder yang menggunakan referensi berupa Rencana Strategis PTOP 2015 - 2019, sedangkan untuk memperoleh data primer dilakukan menggunakan teknik 
wawancara. Teknik wawancara ini dilakukan secara online (menggunakan koneksi internet) maupun offline (bertatap muka). Wawancara dilakukan kepada narasumber berdasarkan RACI dari setiap management objectives yang nantinya akan menghasilkan data primer. Tujuan utama dilakukannya wawancara tahap satu yaitu untuk mengisi nilai faktor desain agar mendapatkan nilai management objectives mana saja yang penting (bernilai positif) dan tidak penting (bernilai negatif), sedangkan untuk wawancara tahap kedua, dilakukan dilakukan untuk menentukan capability level saat ini.

\subsection{Sampel Penelitian}

Survei dilakukan dua kali pada penelitian ini dengan narasumber yang berbeda. Survei pertama, terdapat tiga narasumber untuk mengetahui aspek yang berkaitan dengan TI di PTOP. Survei kedua, terdapat dua narasumber yang hasil wawancaranya akan digunakan untuk menentukan capability level.

Bagian ini memuat langkah-langkah peneliti dalam melakukan penelitian, disajikan secara lengkap namun padat. Kalau melakukan pendataan harus dijelaskan mulai dari metode pengambilan sampel sampai dengan teknik analisis.

Narasumber yang dibutuhkan pada bagian awal adalah 3 orang yang terkait dengan dampak isu universal dan aspek IT universitas. Pada bagian kedua, terdapat 2 narasumber untuk memastikan Capability Level. Untuk memberikan pertanyaan kepada pembicara, mereka akan dicantumkan dalam Tabel 2.

\subsection{Alat Pengolahan Data}

Penelitian ini menggunakan tools atau alat yang sudah disediakan langsung dari COBIT 2019 bernama design toolkit untuk mengolah data primer. Design toolkit merupakan file excel, terdapat beberapa sheet yang sudah diberikan rumus untuk mengolah data faktor desain, juga terdapat hasil output berupa grafik.

\begin{tabular}{cll} 
Tabel & 2. Pembagian Pertanyaan Kepada Narasumber \\
\hline No. & Jabatan/Peran RACI & \multicolumn{1}{c}{$\begin{array}{c}\text { Rujukan } \\
\text { Pertanyaan }\end{array}$} \\
\hline 1. & $\begin{array}{l}\text { Direktur TI PTOP } \\
\text { Wakil Direktur TI }\end{array}$ & $\begin{array}{l}\text { Pertanyaan terkait masalah } \\
\text { faktor desain }\end{array}$ \\
3. & $\begin{array}{l}\text { PTOP } \\
\text { Kepala Teknologi } \\
\text { Informasi Pendidikan }\end{array}$ & \\
PTOP & $\begin{array}{l}\text { Peran CEO dan CIO } \\
\text { pada RACI }\end{array}$ & \\
5. & $\begin{array}{l}\text { Peran Head IT } \\
\text { operation pada RACI }\end{array}$ & $\begin{array}{l}\text { Pertanyaan terkait aktivitas } \\
\text { untuk menentukan } \\
\text { Capability Level }\end{array}$ \\
6. & $\begin{array}{l}\text { Peran CIO pada } \\
\text { RACI }\end{array}$ & \\
\hline
\end{tabular}

\section{Hasil dan Pembahasan}

\subsection{Pengolahan Data}

A. Pengolahan Data Faktor Desain

Pengolahan data faktor desain ini menggunakan empat langkah dari design workflow. Berikut penjabarannya.

- Pemahaman Konteks dan Strategi PTOP

Berdasarkan data utama, langkah pertama adalah menggunakan data utama dan data tambahan (Renstra) untuk memahami strategi, tujuan, profil risiko TI dan isu-isu terkait TI PTOP.

- Penentuan initial scope dari Sistem Tata Kelola

Pada langkah ini, ringkasan sementara akan dibuat untuk nilai tujuan manajemen di domain MEA dan DSS, dengan peringkat prioritas sementara, yang dapat diringkas dalam Tabel 3, Tabel 4 dan Gambar 3 untuk mendapatkan nilai yang terperinci, dimana sumbu y mewakili nilai prioritas sementara setiap management objectives yang memiliki rentang antara seratus (100) sampai dengan minus seratus (-100) dan sumbu $\mathrm{x}$ mewakili jenis management objectives domain DSS dan MEA yang memiliki nilai prioritas sementara.

Tabel 3. Hasil Data Primer Faktor Desain 1-4

\begin{tabular}{|c|c|c|}
\hline No & $\begin{array}{l}\text { Faktor } \\
\text { Desain }\end{array}$ & Hasil Data Primer \\
\hline 1 & $\begin{array}{l}\text { Strategi } \\
\text { Perusahaan }\end{array}$ & $\begin{array}{l}\text { Strategi utama yang digunakan yaitu } \\
\text { orientasi pada mahasiswa atau kestabilan } \\
\text { layanan dan inovasi. }\end{array}$ \\
\hline 2 & $\begin{array}{l}\text { Tujuan } \\
\text { Perusahaan }\end{array}$ & $\begin{array}{l}\text { Tujuan generik PTOP mencakup semua } \\
\text { tujuan generik perusahaan dari COBIT } \\
\text { 2019/ dapat disimpulkan bahwa } 13 \text { tujuan } \\
\text { generik berperan penting bagi PTOP. }\end{array}$ \\
\hline 3 & $\begin{array}{l}\text { Profil } \\
\text { Risiko TI }\end{array}$ & $\begin{array}{l}\text { Risiko TI pada PTOP tergolong pada } \\
\text { peringkat yang sangat tinggi. }\end{array}$ \\
\hline 4 & $\begin{array}{l}\text { Isu Terkait } \\
\text { T\&I }\end{array}$ & $\begin{array}{l}\text { PTOP secara garis besar tidak memiliki isu } \\
\text { terkait TI. }\end{array}$ \\
\hline
\end{tabular}

Tabel 4. Nilai prioritas Management Objectives DSS01MEA04

\begin{tabular}{lcl}
$\begin{array}{c}\text { Bernilai Negatif/Nol } \\
\text { (Tidak Penting) }\end{array}$ & Domain & \multicolumn{1}{c}{$\begin{array}{c}\text { Bernilai Positif } \\
\text { (Penting) }\end{array}$} \\
\hline DSS05, DSS06 & DSS & $\begin{array}{l}\text { DSS01, DSS02, DSS03, } \\
\text { DSS04. }\end{array}$ \\
MEA01, MEA02, & MEA & - \\
MEA03, MEA04 & & \\
\hline
\end{tabular}

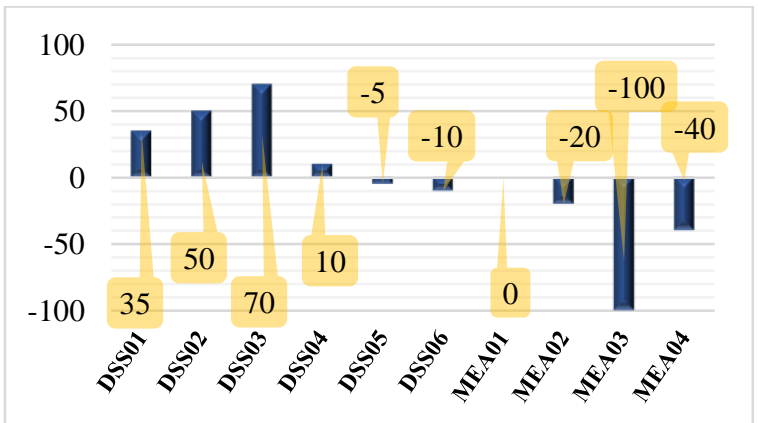

Gambar 3. Grafik nilai prioritas sementara pada Management Objectives domain DSS dan MEA. 
- Perbaikan Lingkup Sistem Tata Kelola

Pada langkah ketiga, berdasarkan data asli mencantumkan status PTOP berdasarkan faktor situasi ancaman, persyaratan kepatuhan, peran TI, model sumber TI, metode implementasi TI, dan strategi pemanfaatan teknologi.

\section{- Simpulan Desain Sistem}

Pada langkah ini, dilakukan penyatuan semua data yang sudah didapat pada langkah-langkah sebelumnya agar mendapatkan prioritas management objectives. Dapat dilihat pada Tabel 5 mengenai simpulan nilai prioritas management objectives untuk domain DSS dan MEA.

Tabel 5. Simpulan nilai prioritas management objectives DSS01-MEA04

\begin{tabular}{lcl}
\hline $\begin{array}{c}\text { Bernilai Negatif/Nol } \\
\text { (Tidak Penting) }\end{array}$ & Domain & \multicolumn{1}{c}{$\begin{array}{c}\text { Bernilai Positif } \\
\text { (Penting) }\end{array}$} \\
\hline- & DSS & $\begin{array}{l}\text { DSS01, DSS02, DSS03, } \\
\text { DSS04, DSS05, DSS06 } \\
\text { MEA04 }\end{array}$ \\
\hline
\end{tabular}

Grafik akhir dari tahap simpulan desain sistem ini dapat dilihat pada Gambar 4, dimana sumbu y mewakili nilai prioritas akhir setiap management objectives yang memiliki rentang antara seratus (100) sampai dengan minus enam puluh (-60) dan sumbu $\mathrm{x}$ mewakili jenis management objectives domain DSS dan MEA yang memiliki nilai prioritas akhir.

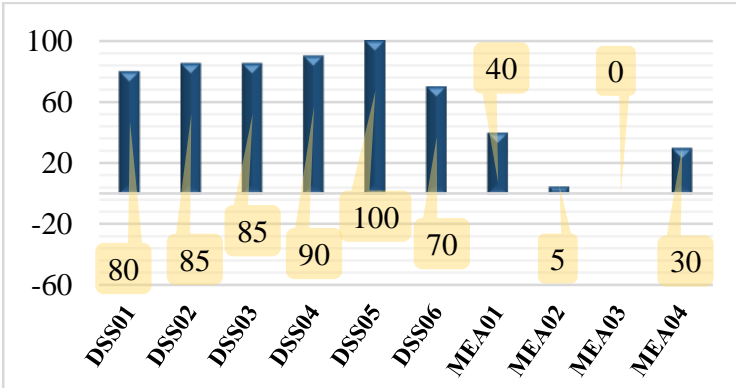

Gambar 4. Grafik simpulan nilai akhir prioritas DSS \& MEA

\section{B. Pengolahan Data Aktivitas}

Hasil wawancara digunakan untuk menentukan capability level saat ini. Wawancara dilakukan kepada narasumber tertentu dengan menggunakan aktivitas yang dimiliki management objectives domain MEA dan DSS pada COBIT 2019.

Berdasarkan data yang telah didapatkan, pertanyaan untuk CEO pada management practice MEA01.01 pada Tabel 6, memiliki rata - rata sebesar $15 \%$ atau dapat dikatakan jika menurut peran CEO aktivitas yang berkaitan dengan penetapan pendekatan monitoring pada PTOP belum tercapai atau belum pernah dilakukan, sehingga kodenya $\mathrm{N}$ (0-15\%). Selanjutnya, pertanyaan untuk CIO, rata - rata yang didapat untuk MEA01.01 adalah 27\% atau dapat dikatakan jika menurut peran CIO aktivitas yang berkaitan dengan penetapan pendekatan monitoring pada PTOP jarang dilakukan atau sebagian sudah tercapai. Terakhir, pertanyaan untuk HIO, rata - rata yang didapatkan untuk MEA01.01 adalah 34\% atau dapat dikatakan jika menurut peran HIO aktivitas yang berkaitan dengan penetapan pendekatan monitoring pada PTOP jarang dilakukan atau sebagian sudah tercapai.

Tabel 6. Data Terkait Aktivitas MEA01 Level 2

\begin{tabular}{ccccc}
\hline $\begin{array}{c}\text { Management } \\
\text { Practice }\end{array}$ & CEO & CIO & HIO & Rata-Rata \\
\hline MEA01.01 & $15 \%$ & $27 \%$ & $30 \%$ & $24 \%$ \\
\hline
\end{tabular}

Setelah ketiga peran tersebut ditemukan rata ratanya, maka dilakukan perhitungan kembali untuk menentukan rata - rata total, yaitu dengan menjumlahkan rata - rata tersebut, kemudian dibagi dengan tiga, sehingga ditemukan sebesar $24 \%$ dengan kode P. Dari perhitungan yang sudah dilakukan, dapat disimpulkan bahwa MEA01 harus berhenti di level 1 . Hal ini dikarenakan persentase rata - rata management objective MEA01 belum mencapai skala $\mathrm{F}$ yang memiliki rentang persentase $85 \%$ - $100 \%$ sehingga belum dapat melanjutkan ke level 3 dan juga belum dapat dikategorikan level 2 karena belum mencapai skala L yang memiliki rentang persentase $50 \%-85 \%$.

Berdasarkan data yang telah didapatkan dan ditunjukkan pada tabel 7, pertanyaan untuk CEO pada management practice DSS01.01 tidak memiliki nilai. Selanjutnya, pertanyaan untuk CIO, rata - rata yang didapat untuk DSS01.01 memiliki rata - rata sebesar $10 \%$ atau dapat dikatakan jika menurut peran CIO aktivitas yang berkaitan dengan operational procedures pada PTOP belum tercapai atau belum pernah dilakukan, sehingga kodenya $\mathrm{N}$ (0-15\%). Terakhir, pertanyaan untuk $\mathrm{HIO}$, rata-rata yang didapatkan untuk DSS01.01 adalah 60\% atau dapat dikatakan jika menurut peran HIO aktivitas yang berkaitan dengan operational procedures pada PTOP sebagian sudah tercapai.

Tabel 7. Data Terkait Aktivitas DSS01 Level 2

\begin{tabular}{ccccc}
\hline $\begin{array}{c}\text { Management } \\
\text { Prractice }\end{array}$ & CEO & CIO & HIO & Rata-Rata \\
\hline DSS01.01 & - & $10 \%$ & $60 \%$ & $23 \%$ \\
\hline
\end{tabular}

Setelah ketiga peran tersebut ditemukan rata ratanya, maka dilakukan perhitungan kembali untuk menentukan rata-rata total, yaitu dengan menjumlahkan rata-rata tersebut, kemudian dibagi dengan tiga, sehingga ditemukan sebesar 23\% dengan kode P. Dari perhitungan yang sudah dilakukan, dapat disimpulkan bahwa DSS01 harus berhenti di level 1. Hal ini dikarenakan persentase rata - rata management objective MEA01 belum mencapai skala $\mathrm{F}$ yang memiliki rentang persentase $85 \%-100 \%$ sehingga belum dapat melanjutkan ke level 3 dan juga belum dapat dikategorikan level 2 karena belum mencapai skala L yang memiliki rentang persentase $50 \%-85 \%$. 


\subsection{Hasil Pengolahan Data}

\section{A. Faktor Desain}

Capability level memiliki ketentuan dimana jika nilai prioritas yang dimiliki management objectives adalah :

- Nilai prioritas $\geq 75$, maka level 4 .

- Nilai proritas berada di antara 50 - 74, maka level 3.

- $\quad$ Nilai prioritas antara 25 - 49, maka level 2.

- Nilai prioritas $\leq 24$, maka level 1 (termasuk yang bernilai negatif atau 0 ).

Setelah pengolahan data faktor desain, dihasilkan target capability level yang dapat dilihat pada Tabel 8 .

Tabel 8. Target Capability Level Domain MEA dan DSS

\begin{tabular}{cll}
\hline No. & $\begin{array}{l}\text { Management } \\
\text { Objectives }\end{array}$ & $\begin{array}{l}\text { Target } \\
\text { Capability Level }\end{array}$ \\
\hline 1. & MEA01 & 2 \\
2. & MEA02 & 1 \\
3. & MEA03 & 1 \\
4. & MEA04 & 2 \\
5. & DSS01 & 4 \\
6. & DSS02 & 4 \\
7. & DSS03 & 4 \\
8. & DSS04 & 4 \\
9. & DSS05 & 4 \\
10. & DSS06 & 3 \\
\hline
\end{tabular}

\section{B. Mencari Capability Level Saat Ini}

Berdasarkan hasil wawancara untuk data aktivitas, hasil dari capability level saat ini menunjukkan bahwa PTOP berada pada level 1 dengan perolehan nilai rata - rata sebesar 34\% dengan kode P, dapat dikatakan jika sebagian sudah tercapai. Dapat disimpulkan jika dalam menerapkan tata kelola teknologi informasi, PTOP belum menerapkan standar yang baik. Capability level saat ini pada PTOP dapat dilihat pada Tabel 9.

Dari data yang didapat, rata-rata pada domain MEA adalah 31\% dan domain DSS adalah 35\%. Dapat dilihat dari tabel di atas, jika pengolahan data faktor desain memengaruhi pengolahan data aktivitas, (contoh MEA03):

MEA03 - berdasarkan tabel tersebut, mengelolaan kepatuhan dengan persyaratan eksternal dianggap tidak penting dilakukan oleh PTOP. Dalam pelaksanaannya kurang lebih sudah tercapai tujuannya dengan melakukan serangkaian kegiatan yang tidak lengkap menurut standar.

Tabel 9. Capability Level Saat Ini Domain MEA dan DSS

\begin{tabular}{llcl}
\hline $\begin{array}{c}\text { Management } \\
\text { Objectives }\end{array}$ & Rata-rata & $\begin{array}{c}\text { Capability } \\
\text { Level saat ini }\end{array}$ & Keterangan \\
\hline MEA01 & $24 \%(\mathrm{P})$ & 1 & Penting \\
MEA02 & $36 \%(\mathrm{P})$ & 2 & Penting \\
MEA03 & $40 \%(\mathrm{P})$ & 1 & $\begin{array}{l}\text { Tidak } \\
\text { Penting }\end{array}$ \\
MEA04 & $25 \%(\mathrm{P})$ & 1 & Penting \\
DSS01 & $34 \%(\mathrm{P})$ & 1 & Penting \\
DSS02 & $41 \%(\mathrm{P})$ & 1 & Penting \\
DSS03 & $39 \%(\mathrm{P})$ & 1 & Penting \\
DSS04 & $25 \%(\mathrm{P})$ & 1 & Penting \\
DSS05 & $38 \%(\mathrm{P})$ & 1 & Penting \\
DSS06 & $35 \%(\mathrm{P})$ & 1 & Penting \\
\hline
\end{tabular}

DSS01 - berdasarkan tabel tersebut, pengelolaan operasi (managed opearation) dianggap tidak terlalu penting dilakukan oleh PTOP. Dalam proses implementasi, tujuan tersebut sedikit banyak tercapai namun kegiatan yang dilaksanakan tidak lengkap dan tidak memenuhi standar.

Pada draft hasil audit tahun 2013 oleh Biro di PTOP pada tahun 2013, seperti ditunjukkan Tabel 10, didapatkan hasil bahwa tata kelola teknologi informasi PTOP yang berjalan dalam kebijakan pengambilan data dilakukan di setiap fakultas, perubahan data yang terjadi belum secara realtime, belum memiliki data yang terpusat, masing-masing fakultas mempunyai sistem informasi yang dibangun secara mandiri, sehingga untuk korelasi data mengalami kesulitan, dan laporan pada tingkat ekselutif yang belum dibuat optimal.

Tabel 10. Perbandingan kondisi tata kelola TI tahun 2013 dan tahun 2019.

\begin{tabular}{|c|c|c|c|}
\hline \multicolumn{2}{|c|}{ Keadaan PTOP tahun 2013} & \multicolumn{2}{|c|}{ Keadaan PTOP tahun 2019} \\
\hline Maturity level & Nilai $=$ & Capability & Nilai $=33 \%$ \\
\hline \multirow[t]{2}{*}{ DS \& ME } & 2,78 & Level DSS & Level $=1$ \\
\hline & Level $=2$ & $\&$ MEA & \\
\hline Maturity & Nilai $=$ & Capability & Nilai $=31 \%$ \\
\hline \multirow[t]{2}{*}{ Level ME } & 2,92 & Level & Level $=1$ \\
\hline & Level $=2$ & MEA & \\
\hline Maturity & Nilai $=$ & Capability & Nilai $=35 \%$ \\
\hline \multirow[t]{2}{*}{ Level DS } & 2,64 & Level DSS & Level $=1$ \\
\hline & Level $=2$ & & \\
\hline Kesimpulan & \multicolumn{3}{|c|}{$\begin{array}{l}\text { Keadaan tata kelola TI pada PTOP saat ini } \\
\text { mengalami peningkatan setelah dilakukan } \\
\text { penelitian pada tahun 2013, namun masih } \\
\text { dalam proses untuk mencapai hasil yang } \\
\text { maksimal. Pelaksanaan tata kelola pada } \\
\text { PTOP saat ini kurang lebih sudah mencapai } \\
\text { tujuannya, namun masih terdapat serangkaian } \\
\text { kegiatan yang tidak lengkap sesui standar } \\
\text { dan belum mengoptimalkan aset TI secara } \\
\text { efektif. }\end{array}$} \\
\hline
\end{tabular}

\subsection{Analisis Gap}

Tahap ini dilakukan analisis gap atau kesenjangan. Gap didapat dari capability level target dikurangi capability level saat ini. Capabiliy level saat ini dihasilkan dari pengolahan data aktivitas, sedangkan target capability level didapat dari pengolahan data faktor desain.

Setelah mendapatkan gap seperti pada Tabel 11, dapat disimpulkan bahwa management objectives yang sudah memenuhi atau dapat dikatakan belum mencapai target. Contoh analisis kesenjangan adalah sebagai berikut:

MEA01 berada pada level 1 (satu) dengan target capability level 2 (dua). Hal tersebut disebabkan dalam melakukan serangkaian aktivitas yang berkaitan dengan mengelola kinerja dan memantau kesesuaian tergolong jarang dilakukan.

DSS01 berada pada level 1 (satu) dengan target capability level 4 (empat). Proses tersebut kurang lebih mencapai tujuannya dengan mengadopsi serangkaian aktivitas yang tidak lengkap, yang dapat 
diklasifikasikan sebagai aktivitas awal atau aktivitas intuitif-tidak terlalu terorganisir dengan baik.

Tabel 11. Gap pada Domain MEA dan DSS

\begin{tabular}{clll}
\hline No. & $\begin{array}{c}\text { Management } \\
\text { Objectives }\end{array}$ & GAP & Keterangan \\
\hline 1 & MEA01 & 1 & Belum Tercapai \\
2 & MEA02 & - & Tercapai \\
3 & MEA03 & -2 & Tercapai \\
4 & MEA04 & 1 & Belum Tercapai \\
5 & DSS01 & 3 & Belum Tercapai \\
6 & DSS02 & 3 & Belum Tercapai \\
7 & DSS03 & 3 & Belum Tercapai \\
8 & DSS04 & 3 & Belum Tercapai \\
9 & DSS05 & 3 & Belum Tercapai \\
10 & DSS06 & 2 & Belum Tercapai \\
\hline
\end{tabular}

\subsection{Rekomendasi}

Pada tahap ini, untuk management objectives yang memiliki gap atau kesenjangan antara capability level saat ini dengan agreed capability level, maka terdapat rekomendasi yang sudah disediakan dari COBIT 2019 beserta sumber yang sekiranya dapat dijadikan bahan pembelajaran untuk meningkatkan kualitas TI di PTOP. Rekomendasi diberikan hanya pada management objectives yang terdapat gap saja, jika tidak ada gap, maka tidak perlu dilakukan analisis karena dianggap sudah dapat memenuhi management objectives tersebut.

Berikut contoh rekomendasi yang diberikan oleh COBIT 2019 berdasarkan management objectivesnya:

\section{Rekomendasi MEA01}

Kemampuan yang harus dimiliki para staf maupun petinggi adalah conformance review, ICT quality management, dan quality assurance. Kemudian, kebijakan yang harus ditetapkan adalah kebijakan penilaian diri dan kebijakan whistle-blower. Selain itu, budaya yang harus ditanamkan adalah peningkatan berkelanjutan dari bisnis dan proses I\&T.

\section{Rekomendasi DSS01}

Kemampuan yang harus dimiliki para staf maupun petinggi adalah database administration, facilities management, it infrastructure methods and tools, service delivery, dan storage management. Kemudian kebijakan yang harus ditetapkan adalah kebijakan manajemen layanan. Selain itu, budaya yang harus ditanamkan adalah menciptakan budaya keunggulan di seluruh organisasi, menciptakan lingkungan yang dimana prosedur operasional memberikan layanan yang diperlukan dan mencoba ide-ide baru, mengelola keunggulan operasional melalui keterlibatan karyawan dan peningkatan berkelanjutan, serta menerapkan pendekatan yang berpusat pada pelanggan (untuk pelanggan internal dan eksternal).

\section{Kesimpulan}

PTOP memiliki nilai Capability Level tertinggi pada proses DSS02 Managed Service Requests and Incident yang memiliki nilai 54\% dan PTOP memiliki nilai Capability Level terendah pada proses MEA01 Managed Performance and Conformance Monitoring dengan nilai $24 \%$.

Dapat ditarik kesimpulan bahwa PTOP memiliki rata - rata persentase pada domain DSS dan MEA sebesar $33 \%$ sehingga memiliki kode P. Artinya bahwa PTOP kurang lebih sudah mencapai tujuannya, namun masih belum mencapai capability level yang telah ditargetkan karena serangkaian aktivitas yang masih kurang lengkap dan belum rutin dilakukan.

\section{Daftar Pustaka}

Anggito, A dan Setiawan, J., 2018. Metodologi Penelitian Kualitatif. Sukabumi.

Barkah, A.S dan Dianingrum, M., 2015. Evaluasi penerapan sistem informasi dan teknologi nformasi menggunakan COBIT Framework di STMIK AMIKOM Purwokerto. J. Probisnis, 8(1): 22-30.

Hardiansyah, E., Darwiyanto, E dan Asror I., 2019. Audit tata kelola teknologi informasi menggunakan framework COBIT 5 pada Domain DSS dan MEA (Studi Kasus : Bappeda Kabupaten Tulungagung). e-Proceeding Eng 6(2):8727-8740.

ISACA, 2018. COBIT 2019: Implementing and Optimizing an Information and Technology Governance Solution.

ISACA, 2018. Introducing COBIT 2019 - Overview November 2018

Juliandarini dan Sri, H., 2013. Audit sistem informasi pada Digilib PTOP menggunakan kerangka kerja COBIT 4.0. Jurnal Sarjana Teknik Informatika 1(1): 276-286.

Setiaji, B dan Dewi, U., 2016. Sistem informasi manajemen proyek di PT. Panorama Graha Asri. Jurnal Ilmiah Komputer dan Informatika (KOMPUTA).

Sudjana, 2006. Metoda Statistika Cetakan 6. Bandung. Sugiyono, 2008. Metode Penelitian Pendidikan Pendekatan Kuantitatif dan R\&D. Bandung.

Sugiyono, 2009. Metode Penelitian Kuantitatif, Kualitatif dan R\&D. Bandung.

Sukirni, D., 2012. Kepemilikan manajerial, kepemilikan institusional, kebijakan deviden dan kebijakan hutang analisis terhadap nilai perusahaan. Accounting Analysis Journal.1(2).

Grembergen, W.V. and De Haes, S., 2009. Enterprise Governance Of Information Technology: Achieving Strategic Alignment And Value. 